\title{
Computation of Non-Isothermal Reversed Stagnation-Point Flow over a Flat Plate
}

\author{
Vai Kuong Sin and Chon Kit Chio \\ University of Macau \\ Taipa, Macao SAR, China
}

\section{Introduction}

The full Navier-Stokes equations are difficult or impossible to obtain an exact solution in almost every real situation because of the analytic difficulties associated with the nonlinearity due to convective acceleration. The existence of exact solutions are fundamental not only in their own right as solutions of particular flows, but also are agreeable in accuracy checks for numerical solutions.

In some simplified cases, such as two-dimensional stagnation point flows, by introducing coordinate variable transformation, the number of independent variables is reduced by one or more. The governing equations can be simplified to the non-linear ordinary differential equations and are analytic solvable. The classic problems of two-dimensional stagnation-point flows can be analyzed exactly by Hiemenz Hiemenz (1911), one of Prandtl's first students. These are exact solutions for flow directed perpendicular to an infinite flat plate. Howarth Howarth (1951) and Davey Davey (1961) extended the two-dimensional and axisymmetric flows to three dimensions, which is based on boundary layer approximation in the direction normal to the plane.

The similarity solutions for the temperature field were studied by Eckert Eckert (1942). Case corresponding a step change in wall temperature or in wall heat flux in laminar steady flows at a stagnation point has been also investigated by several authors (see Chao et al. Chao \& Jeng (1965), Sano Sano (1981) and Gorla Gorla (1988)). Further, Lok et al. Lok et al. (2006) investigated the mixed convection near non-orthogonal stagnation point flow on a vertical plate with uniform surface heat flux, where the results published are very good with present value of $\theta(0)$ for the constant wall temperature boundary condition. On the contrary, reversed stagnation-point flow over an infinite flat wall does not have analytic solution in two-dimensional steady state case.

The aim of this study is to investigate the unsteady viscous reversed non-isothermal stagnation-point flow, which is started impulsively in motion with a constant velocity away from near the stagnation point. A similarity solution of full Navier-Stokes equations and energy equation are solved by applying numerical method. Studies of the reversed stagnation-point flow have been considered during the last few years, as this flow can be applied in different important applications that occur in oil recovery industry, as shown in Fig. (1). 


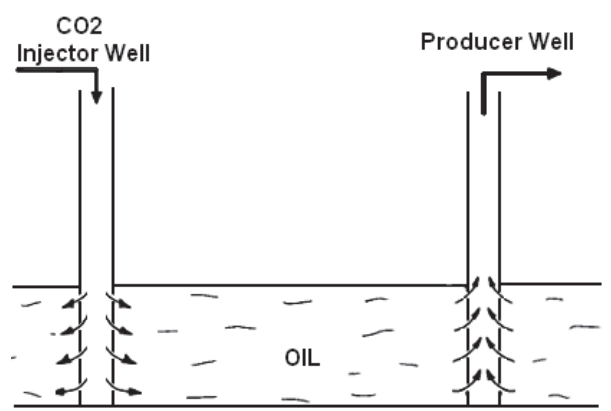

Fig. 1. Oil recovery industry

\section{Governing equation}

\subsection{Momentum equation}

The viscous fluid flows in a rectangular Cartesian coordinates $(x, y, z)$, Fig. 2, which illustrates the motion of external flow directly moves perpendicular out of an infinite flat plane wall. The origin is the so-called stagnation point and $z$ is the normal to the plane.

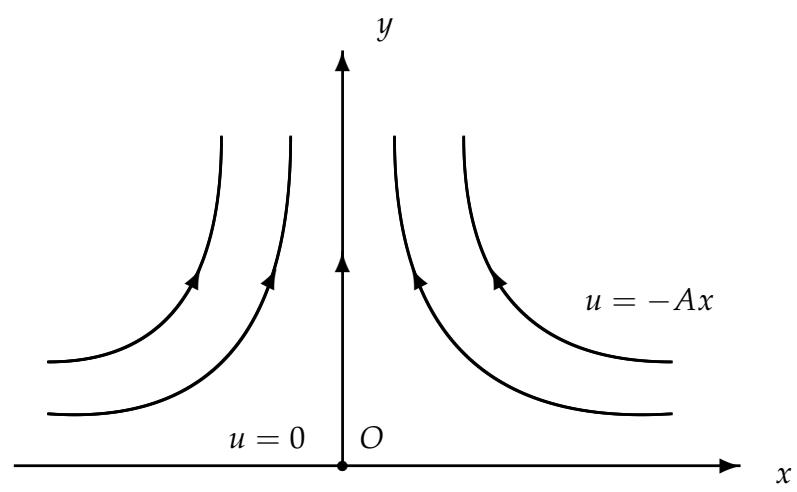

Fig. 2. Cooridnate system of reversed stagnation-point flow

By conservation of mass principle with constant physical properties, the equation of continuity is:

$$
\frac{\partial u}{\partial x}+\frac{\partial v}{\partial y}=0
$$

We consider the two-dimensional reversed stagnation-point flow in unsteady state and the flow is bounded by an infinite plane $y=0$, the fluid remains at rest when time $t<0$. At $t=0$, it starts impulsively in motion which is determined by the stream function

$$
\psi=-\alpha x y
$$

For a viscid fluid the stream function, since the flow motion is determined by only two factors, the kinematic viscosity $v$ and $\alpha$, we consider the following modified stream function 


$$
\begin{gathered}
\psi=-\sqrt{A v} x f(\eta, \tau) \\
\eta=\sqrt{\frac{A}{v}} y \\
\tau=A t
\end{gathered}
$$

where $\eta$ is the non-dimensional distance from wall and $\tau$ is the non-dimensional time. Noting that the stream function automatically satisfies equation of continuity 1 . The Navier-Stokes equations White (2003) governing the unsteady flow with constant physical properties are

$$
\begin{aligned}
& \frac{\partial u}{\partial t}+u \frac{\partial u}{\partial x}+v \frac{\partial u}{\partial y}=-\frac{1}{\rho} \frac{\partial p}{\partial x}+v\left(\frac{\partial^{2} u}{\partial x^{2}}+\frac{\partial^{2} u}{\partial y^{2}}\right) \\
& \frac{\partial v}{\partial t}+u \frac{\partial v}{\partial x}+v \frac{\partial v}{\partial y}=-\frac{1}{\rho} \frac{\partial p}{\partial y}+v\left(\frac{\partial^{2} v}{\partial x^{2}}+\frac{\partial^{2} v}{\partial y^{2}}\right)
\end{aligned}
$$

where $u$ and $v$ are the velocity components along $x$ and $y$ axes, and $\rho$ is the density.

From the definiton of stream function, we have

$$
\begin{gathered}
u=\frac{\partial \psi}{\partial y}=-A x f_{\eta} \\
v=-\frac{\partial \psi}{\partial x}=\sqrt{A v} f
\end{gathered}
$$

Substituting $u$ and $v$ into the governing equations results a simplified partial differential equation

$$
f_{\eta \tau}-\left(f_{\eta}\right)^{2}+f f_{\eta \eta}-f_{\eta \eta \eta}+1=0,
$$

with the boundary conditions

$$
\begin{aligned}
& f(0, \tau)=f_{\eta}(0, \tau)=0 \\
& f_{\eta}(\infty, \tau)=1 .
\end{aligned}
$$

Equation (6) is the similarity equation of the full Navier-Stokes equations at two-dimension reversed stagnation point. The coordinates $x$ and $y$ are vanished, leaving only a dimensionless variable $\eta$.

When the flow is in steady state such that $f_{\eta \tau}=0$, it can be proved that the differential equation does not have solution under the boundary conditions Davey (1961). Thus we concentrate on the transient behavior in other section.

\subsection{Energy equation}

In this section, we shall focus on the non-isothermal flow which is at a temperature $T$ different from that of the wall $T_{w}$. By solving the energy equation, we are able to determine the temperature distribution in the reversed stagnation-point flow. 
For constant-property fluid such as results, the transient energy equation Burmeister (1993) is given as follow

$$
\rho c_{p}\left(\frac{\partial T}{\partial t}+u \frac{\partial T}{\partial x}+v \frac{\partial T}{\partial y}\right)=k\left(\frac{\partial^{2} T}{\partial x^{2}}+\frac{\partial^{2} T}{\partial y^{2}}\right)+\mu \Phi
$$

where $k$ is the thermal conductivity and $c_{p}$ is the heat capacity.

Note that $u$ and $v$ are the velocity components. These give

$$
\begin{gathered}
u=-A x f_{\eta} \\
v=\sqrt{A v} f
\end{gathered}
$$

and $\Phi$ is defined as

$$
\Phi=2\left[\left(\frac{\partial u}{\partial x}\right)^{2}+\left(\frac{\partial v}{\partial y}\right)^{2}\right]+\left(\frac{\partial u}{\partial y}+\frac{\partial v}{\partial x}\right)^{2}-\frac{2}{3}\left(\frac{\partial u}{\partial x}+\frac{\partial v}{\partial y}\right)^{2}
$$

and is called the viscous dissipation since it represents the irreversible conservation of mechanical forms of energy to a thermal form.

To transform equation (8) into a nondimensional form, a dimensionless temperature $\theta$ is defined as

$$
\theta=\frac{T-T_{w}}{T_{\infty}-T_{w}} .
$$

where $T_{\infty}$ is the ambient temperature. Noting that both $T_{w}$ and $T_{\infty}$ are constant,

$$
T(0, t)=T_{w}, T(\infty, t)=T_{\infty},
$$

the temperature distribution $T$ can be considered as a function of $y$ and $t$ only.

Under the assumption that the viscous dissipation is negligible compared to conduction at the wall, the energy equation may be written as

$$
\theta_{\eta \eta}-\frac{\rho c_{p} v}{k} f \theta_{\eta}=\frac{\rho c_{p} v}{k} \theta_{\tau}
$$

subject to the boundary conditions

$$
\theta(0, \tau)=0 \quad \theta(\infty, \tau)=1
$$

Equation (13) is a second-order partial differential equation with variable coefficients $f(\eta, \tau)$ and the Prandtl number $P r=\rho c_{p} v / k$ is assumed to be constant. Consider the fluid of which $\operatorname{Pr}=1$, the thermal boundary layer and the velocity boundary layer collapse, and thus, substituting $\theta=f^{\prime}$, equation (6) and (13) represent the same equation.

\section{Asymptotic solution}

\subsection{Velocity distribution}

When $\tau$ is relatively small, Proudman and Johnson Proudman \& Johnson (1962) first considered the early stages of the diffusion of the initial vortex sheet at $y=0$. They suggested that, when the flow is near the plane region, the viscous forces are dominant, and the viscous term in the governing Navier-Stokes equations is important only near the 
boundary. On the contrary, the viscous forces were neglected away from the wall. The convection terms dominate the motion of external flow in considering the inviscid equation in the fluid. According to their solution, the general features of the predicted streamline are sketched in Fig. (3).

We therefore consider the similarity of the inviscid equation

$$
f_{\eta \tau}-\left(f_{\eta}\right)^{2}+f f_{\eta \eta}+1=0
$$

Proudman and Johnson obtained a similarity solution of (15) is in the form

$$
f(\eta, \tau)=e^{\tau} F(\gamma)
$$

and the further integration provides an exact solution

$$
F(\gamma)=\gamma-\frac{2}{c}\left(1-e^{-c \gamma}\right)
$$

where $\mathrm{c}$ is a constant of integration; the improved numerical evaluations of Robins and Howarth Robins \& Howarth (1972) estimate the value of $c$ to be approximately 3.51. This solution describes the flow in the outer region. When $\tau \rightarrow \infty$ and $\eta / e^{\tau}$ is relatively small, the solution (17) yields

$$
F \sim-\gamma=-\eta e^{-\tau}
$$

and

$$
f=-\eta, \quad f^{\prime}=-1
$$

Substituting in equation (6) becomes

$$
f^{\prime \prime \prime}-f f^{\prime \prime}+\left(f^{\prime}\right)^{2}-1=0
$$

with the boundary conditions

$$
\begin{gathered}
f(0)=f^{\prime}(0)=0 \\
f^{\prime}(\infty)=-1
\end{gathered}
$$

This is exactly the classic stagnation-point problem Hiemenz (1911)) by changing the sign in $f$. It is a third-order nonlinear ordinary differential equation and does not have an analytic solution, and thus it is necessary to solve it numerically and the result is show in Fig. 4 .

\subsection{Temperature distribution}

Wen $\tau \rightarrow \infty$, we have an exact solution of the momentum equation in outer region, and thus, we still apply the same procedure to solve the temperature profiles in outer region. Consider the following transformation:

$$
\theta(\eta, \tau)=\Theta(\gamma)
$$

where

$$
\gamma=\eta e^{-\tau}
$$




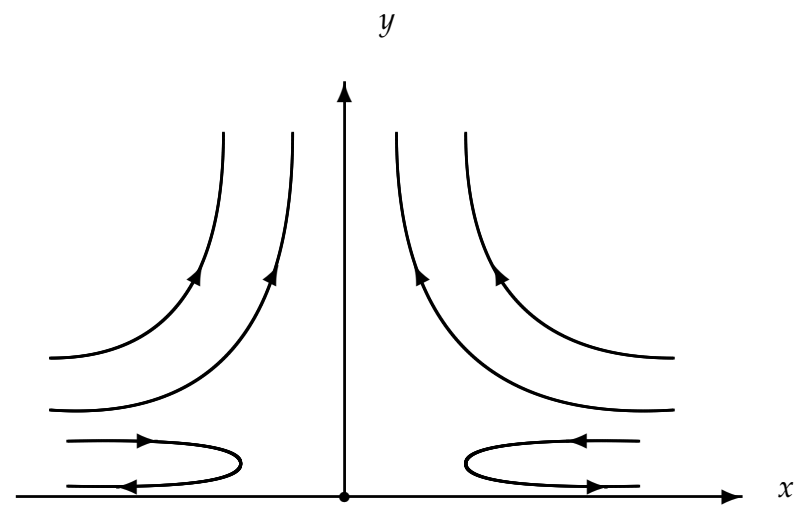

Fig. 3. Streamlines of reversed stagnation-point flow

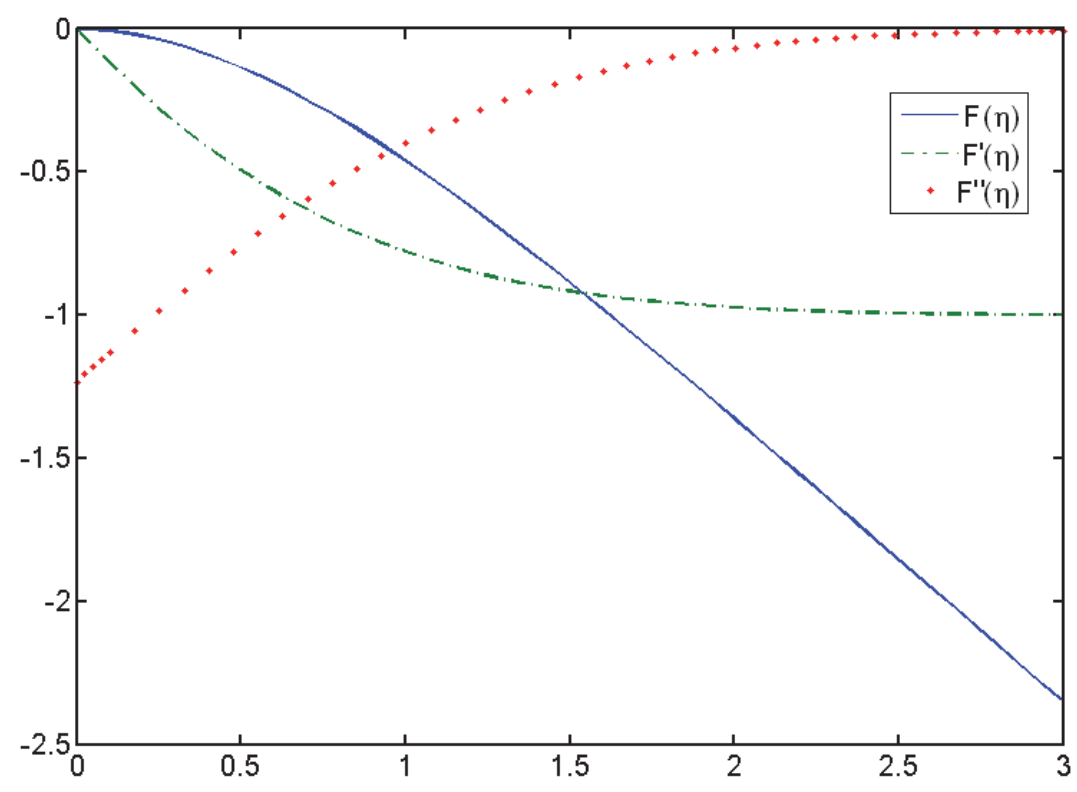

Fig. 4. Numerical solutions of stagnation-point flow 
if we consider a finite value of $\tau$, equation (13) becomes an ordinary differential equation

$$
\Theta^{\prime \prime}+\frac{2 \operatorname{Pr} e^{2 \tau}}{c}\left(1-e^{-c \gamma}\right) \Theta^{\prime}=0
$$

subject to the boundary

$$
\Theta(0)=0, \Theta(\infty)=1
$$

where

$$
c=3.51 \text {. }
$$

The following pages (Figs. (5) to (6)) show the asymptotic solution of temperature distributions with $\mathrm{Pr}$ in outer region.

\section{Finite-difference formulations}

\subsection{Governing equations}

According to the previous work, the governing equations in reversed stagnation-point flow are

$$
\begin{gathered}
f_{\eta \tau}-\left(f_{\eta}\right)^{2}+f f_{\eta \eta}-f_{\eta \eta \eta}+1=0 . \\
\theta_{\eta \eta}-\operatorname{Pr} f \theta_{\eta}=\operatorname{Pr} \theta_{\tau}
\end{gathered}
$$

The above equations (6) and (13) subject to the boundary conditions are are nonlinear third-order partial differential equations. They do not admit similarity solution and numerical or perturbation methods are needed to solve the equation.

We shall, however, use here a numerical method. It is an implicit finite-difference method with second-order accuracy. The partial differential equations can be expressed as approximate expressions, so that it is easy to program the solution of large numbers of coupled equation.

We start with rewriting the partial differential equations in the form:

$$
\begin{gathered}
f_{\eta \tau}=f_{\eta \eta \eta}+\left(f_{\eta}\right)^{2}-1+f f_{\eta \eta} \\
\theta_{\tau}=\frac{1}{P r} \theta_{\eta \eta}-f \theta_{\eta}
\end{gathered}
$$

and introducing the new dependent variables

$$
\begin{gathered}
h=1-f_{\eta} \\
g=\theta
\end{gathered}
$$

The equations can be rewritten as

$$
\begin{gathered}
h_{\tau}=h_{\eta \eta}+2 h-h^{2}+h_{\eta} \int(1-h) d \eta \\
g_{\tau}=\frac{1}{P r} g_{\eta \eta}-g_{\eta} \int(1-h) d \eta
\end{gathered}
$$




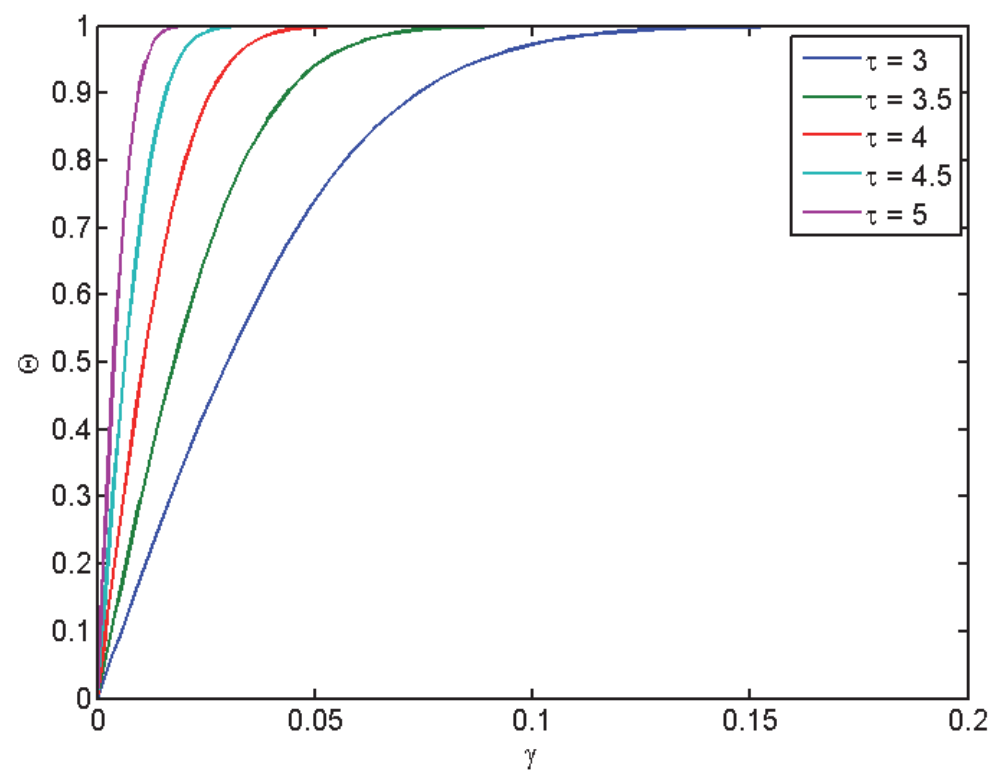

(a) $\operatorname{Pr}=0.7$

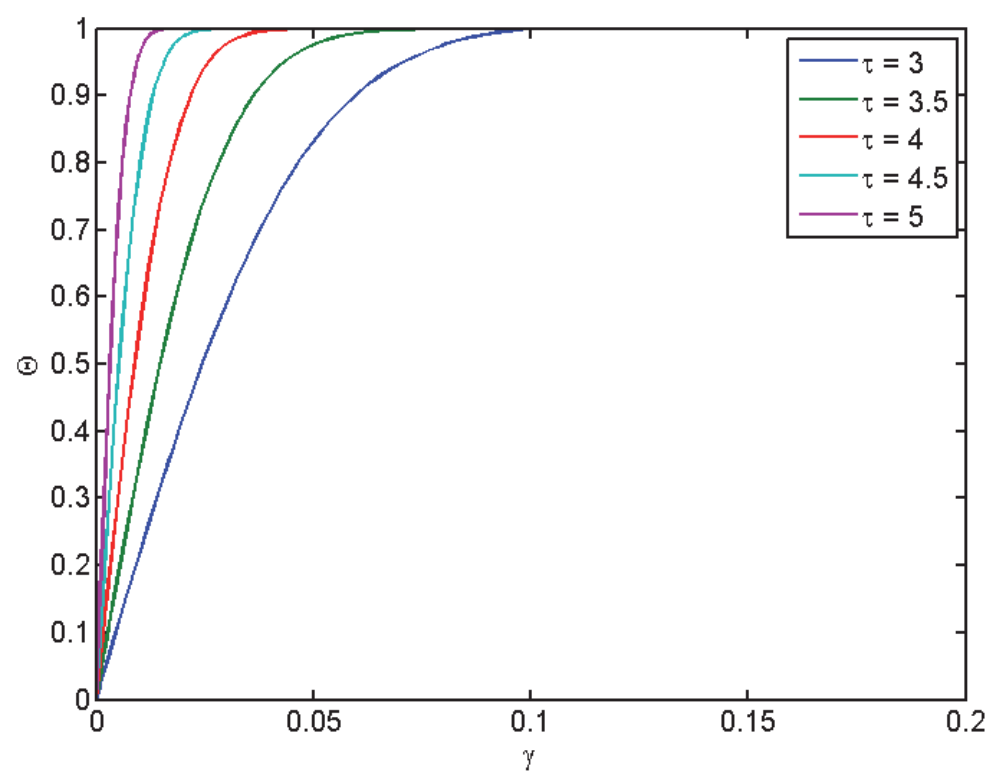

(b) $\operatorname{Pr}=1$

Fig. 5. Asymptotic temperature solution $\Theta$ for various value of $\gamma$ 


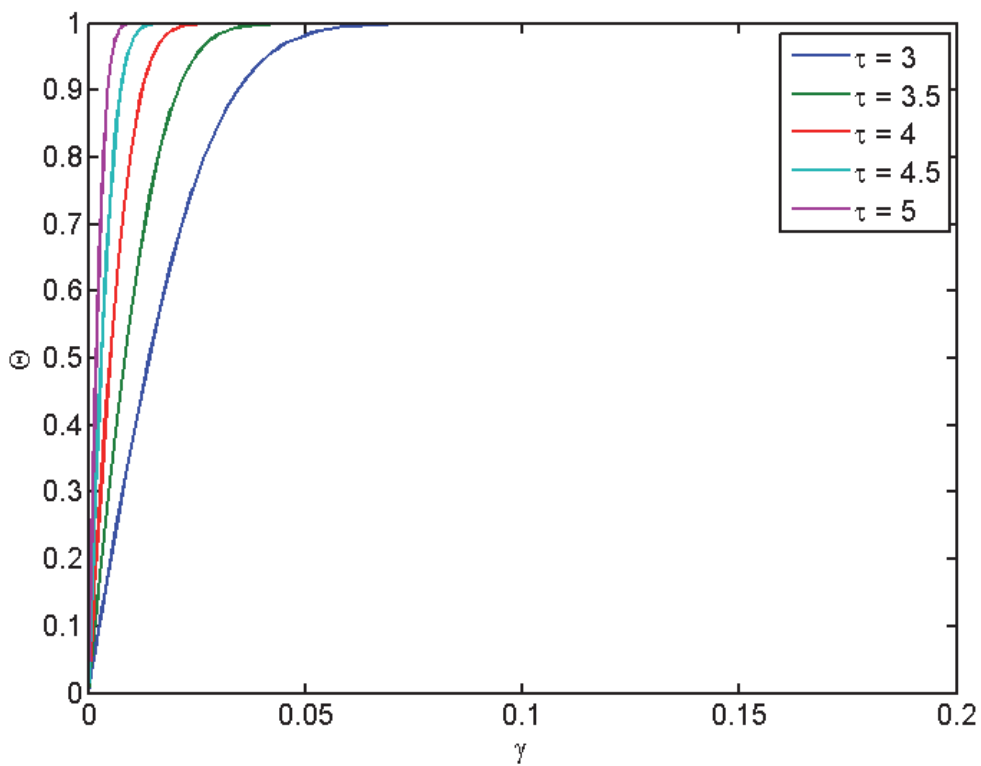

(a) $\operatorname{Pr}=3$

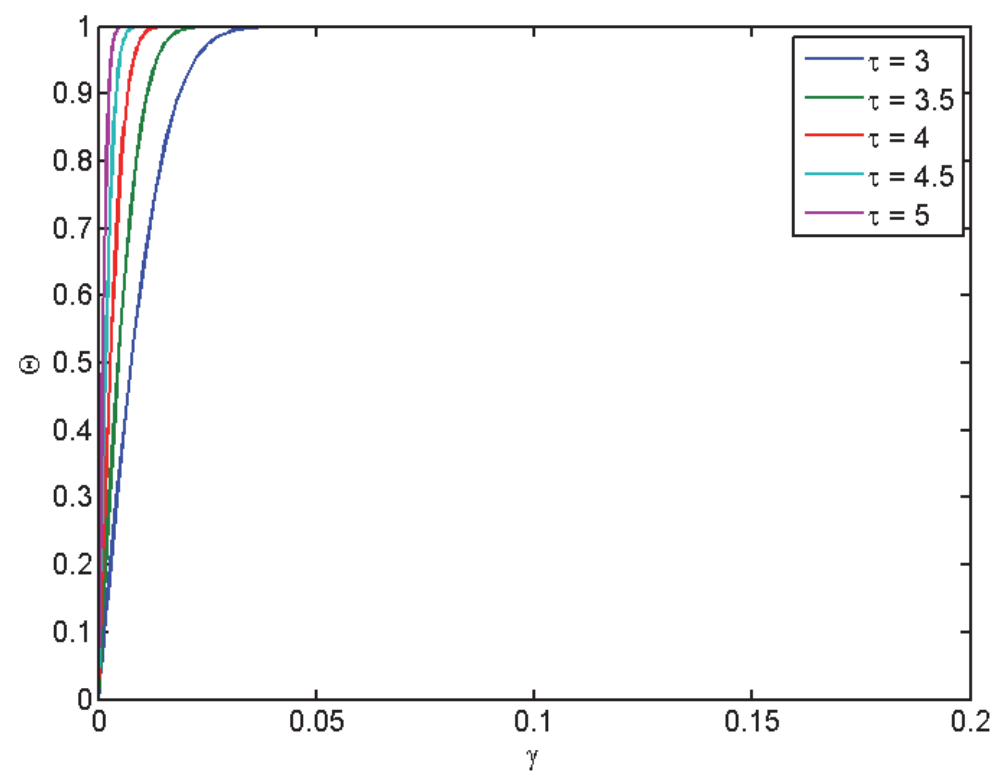

(b) $\operatorname{Pr}=10$

Fig. 6. Asymptotic temperature solution $\Theta$ for various value of $\gamma$ 
We now consider the net rectangle in the $\tau-\eta$ plane shown in Fig. (7) and the net points defined as below:

$$
\begin{aligned}
& \eta^{0}=0, \quad \eta_{j}=\eta_{j-1}+\Delta \eta, \quad j=1,2, \ldots J, \eta_{J}=\eta_{\infty} \\
& \tau^{0}=0, \quad \tau^{n}=\tau^{n-1}++\Delta \tau, \quad n=1,2, \ldots J,
\end{aligned}
$$

Here $n$ and $j$ are just the sequence of numbers that indicate the coordinate location, not tensor indices or exponents. The partial differential equations are easily discretized by central

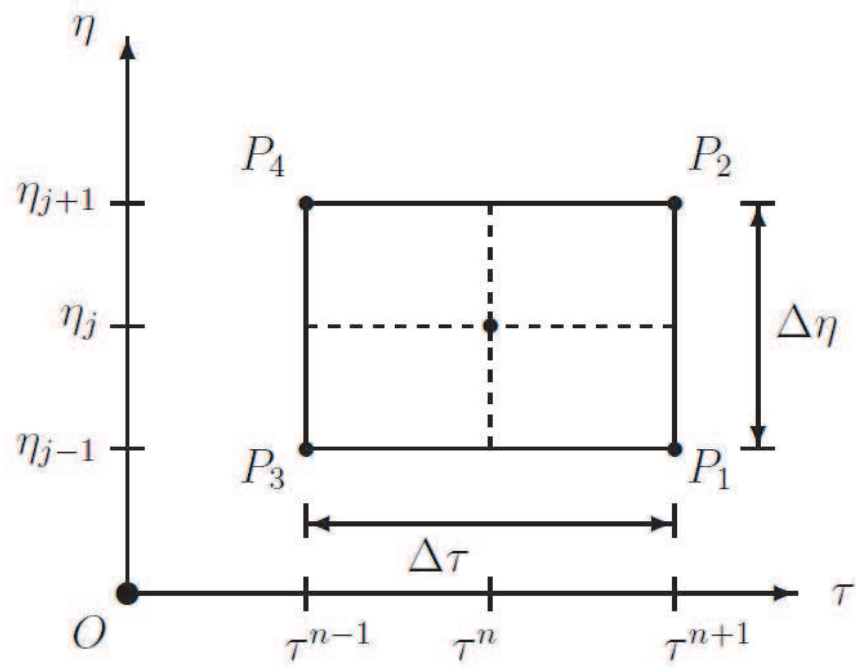

Fig. 7. Net rectangle for finite-difference method

difference representations with second-order accuracy, for example the finite-difference forms for any points are

$$
h_{\eta}=\frac{h_{i+1}^{n}-h_{i-1}^{n}}{2 \Delta \eta}
$$

and

$$
h_{\eta \eta}=\frac{h_{i+1}^{n}-2 h_{i}^{n}+h_{i-1}^{n}}{\Delta \eta}
$$

When $i=0$, since the value of $h_{i-1}^{n}$ is not logical, the derivative is replaced by the forward difference with second-order accuracy

$$
h_{\eta}=\frac{-h_{i+2}^{n}+4 h_{i+1}^{n}-3 h_{i}^{n}}{2 \Delta \eta}
$$


The finite-difference form of the ODE is written for the midpoint $\left(\tau^{n}, \eta_{j}\right)$, the discretized equation takes the form.

$$
\begin{aligned}
\frac{h_{i}^{n+1}-h_{i}^{n}}{\Delta \tau} & =\frac{h_{i+1}^{n+1}-2 h_{i}^{n+1}+h_{i-1}^{n+1}}{(\Delta \eta)^{2}}+2 h_{i}^{n}-\left(h_{i}^{n}\right)^{2} \\
& -\frac{h_{i+1}^{n}-h_{i-1}^{n}}{2 \Delta \eta} \int_{0}^{i \Delta \eta}(1-h) d \eta \\
\frac{g_{i}^{n+1}-g_{i}^{n}}{\Delta \tau} & =\frac{g_{i+1}^{n+1}-2 g_{i}^{n+1}+g_{i-1}^{n+1}}{\operatorname{Pr}(\Delta \eta)^{2}} \\
& -\frac{g_{i+1}^{n}-g_{i-1}^{n}}{2 \Delta \eta} \int_{0}^{i \Delta \eta}(1-h) d \eta
\end{aligned}
$$

This procedure yields the following linear tridiagonal system:

$$
\begin{array}{r}
-\beta h_{i+1}^{n+1}+(1+2 \beta) h_{i}^{n+1}-\beta h_{i-1}^{n+1}=h_{i}^{n}+\Delta \tau\left[2 h_{i}^{n}-\left(h_{i}^{n}\right)^{2}-\frac{h_{i+1}^{n}-h_{i-1}^{n}}{2} \sum_{0}^{i}\left(1-h_{i}^{n}\right)\right] \\
-\frac{\beta}{P r} g_{i+1}^{n+1}+\left(1+\frac{2 \beta}{\operatorname{Pr}}\right) g_{i}^{n+1}-\frac{\beta}{\operatorname{Pr}} g_{i-1}^{n+1}=g_{i}^{n}-\Delta \tau \frac{g_{i+1}^{n}-g_{i-1}^{n}}{2} \sum_{0}^{i}\left(1-h_{i}^{n}\right)(31
\end{array}
$$

where $\beta=\Delta \tau /(\Delta \eta)^{2}$.

\subsection{Initial flow}

The initial condition is the solution of the following linear partial differential equations

$$
\begin{gathered}
h_{\tau}=h_{\eta \eta} \\
g_{\tau}=\frac{1}{P r} g_{\eta \eta}
\end{gathered}
$$

an the required solutions are

$$
\begin{aligned}
& h=1-\operatorname{erf}\left(\frac{\eta}{2 \sqrt{\tau}}\right) \\
& g=\operatorname{erf}\left(\frac{\eta}{2 \sqrt{\tau / P r}}\right)
\end{aligned}
$$

where the error function $\operatorname{erf}(z)$ is defined as

$$
\operatorname{erf}(z)=\frac{2}{\sqrt{\pi}} \int_{0}^{z} \exp \left(-\xi^{2}\right) d \xi
$$


When $\tau \rightarrow 0$, the boundary conditions are convenient to write in the form

$$
\begin{aligned}
& h_{0}^{n}=g_{0}^{n}=0, \\
& h_{i}^{0}=\operatorname{erf}\left(\frac{\eta_{i}}{2 \sqrt{\tau}}\right), \\
& g_{i}^{0}=\operatorname{erf}\left(\frac{\eta_{i}}{2 \sqrt{\tau / P r}}\right)
\end{aligned}
$$

Equations (31) are defined as being implicit, as more than one unknown appears in the left hand side. They are unconditionally stable, however, set of linear algebraic equations is required to be solved by the tridiagonal matrix algorithm (TDMA), also know as the Thomas algorithm, which is a simplified form of Gaussian elimination that is applied to evaluate tridiagonal systems of equations.

The procedure is straightforward, except for the algebra. The resulting algorithm of the finite-difference method is written in MATLAB, a numerical computing environment allowing matrix manipulations and plotting of functions and data.

\section{Numerical result}

The following figure (Figs. (8)) shows the velocity distribution $f$. From the solution 17, we have

$$
\log \left(1-f_{\eta}\right)=-c \eta+\log 2
$$

and if the similarity solution holds, then the graph of $\log \left(1-f_{\eta}\right)$ against $\eta e^{-\tau}$ should provide a straight line of gradient $-c$, except for small values of $\eta$, In Figs. (8), the values of $\log \left(1-f_{\eta}\right)$ are plotted against $\eta e^{-\tau-3.5}$ at different value of $\tau$. The value of $c$ is 3.51 which is consistent with the previous discussion.

Next, we show the numerical solution of temperature distributions with $\operatorname{Pr}$ in Figs. (9) through (10)) . It is noticed that the dimensionless wall temperature gradient $\Theta^{\prime}(0)$ raises with increase of Prandtl number, but the thermal boundary layer thickness decrease with increase of Prandtl number. The thermal boundary layer thickness is the distance from the body at which the temperature is $99 \%$ of the temperature obtained from an inviscid solution. The decrease of thickness can be explained by the definition of Prandtl number that Prandtl number is inversely proportional to the molecular thermal diffusivity $\alpha$. If the Prandtl number is greater than 1 , the thermal boundary layer is thinner than the velocity boundary layer. If the Prandtl number is less than 1, which is the case for air at standard conditions, the thermal boundary layer is thicker than the velocity boundary layer.

In comparison to the asymptotic solution, we note that increase in non-dimensional time $\tau$ leads to an increase in temperature profiles in both cases. Near the wall region where $\gamma$ is small, the dimensionless wall temperature gradient of the numerical solution is lower than that of the asymptotic solution. It is because the asymptotic solution is only valid for the outer region. At our level of discretization, however, we are only able to resolve in small time range. 

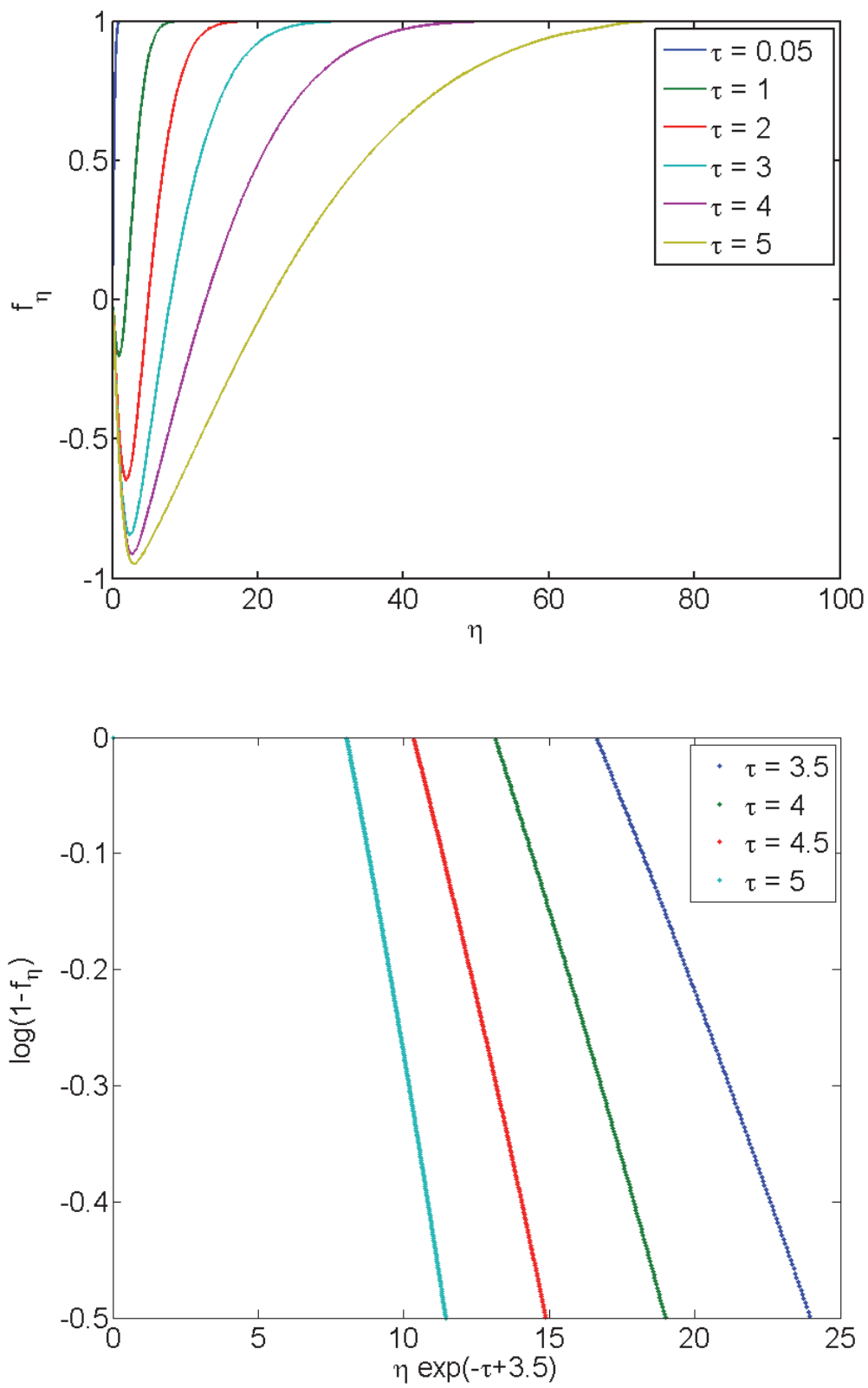

Fig. 8. Numerical solution of Eq. (17) against (a) $\tau$, (b) $\eta e^{-\tau}$ 


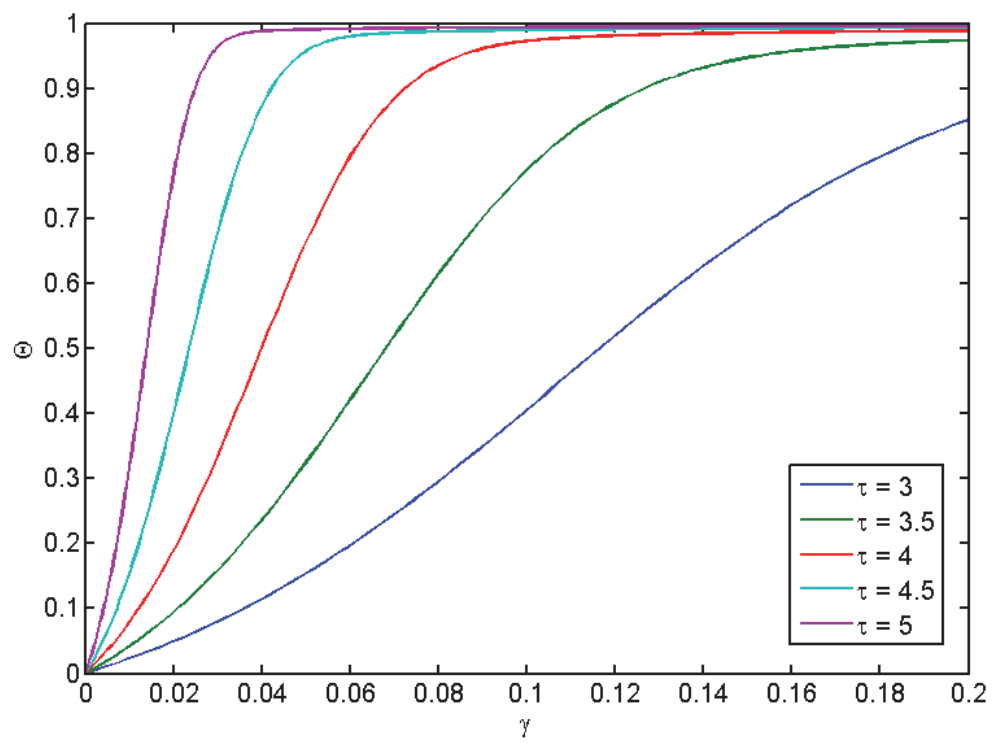

(a) $\operatorname{Pr}=0.7$

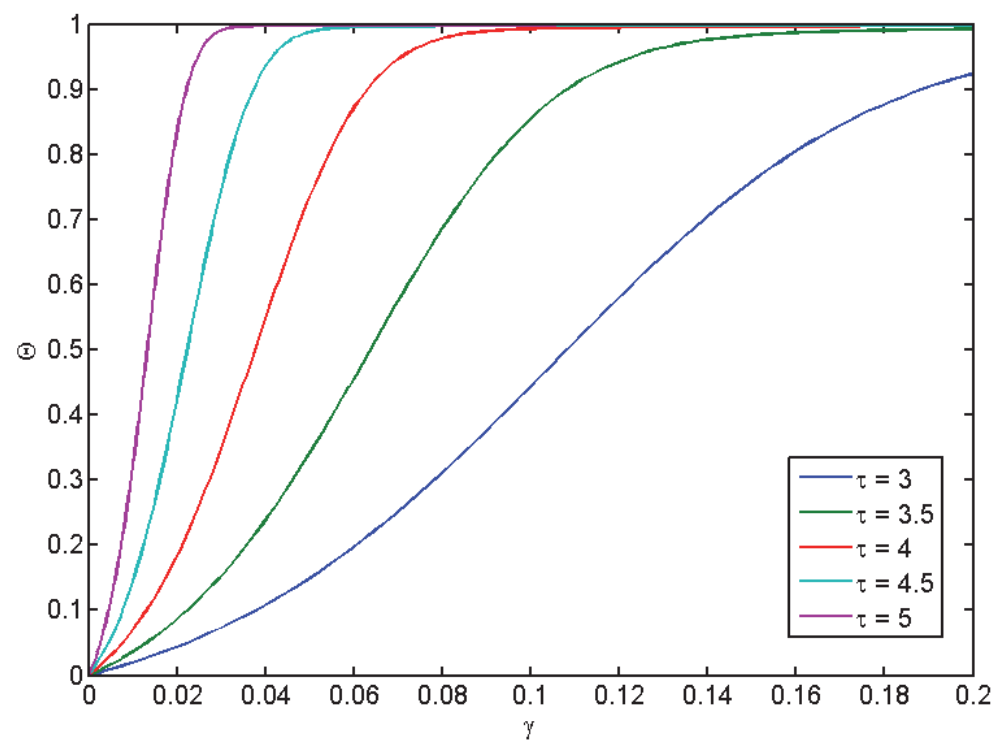

(b) $\operatorname{Pr}=1$

Fig. 9. Numerical temperature solution $\Theta$ for various value of $\gamma$ 


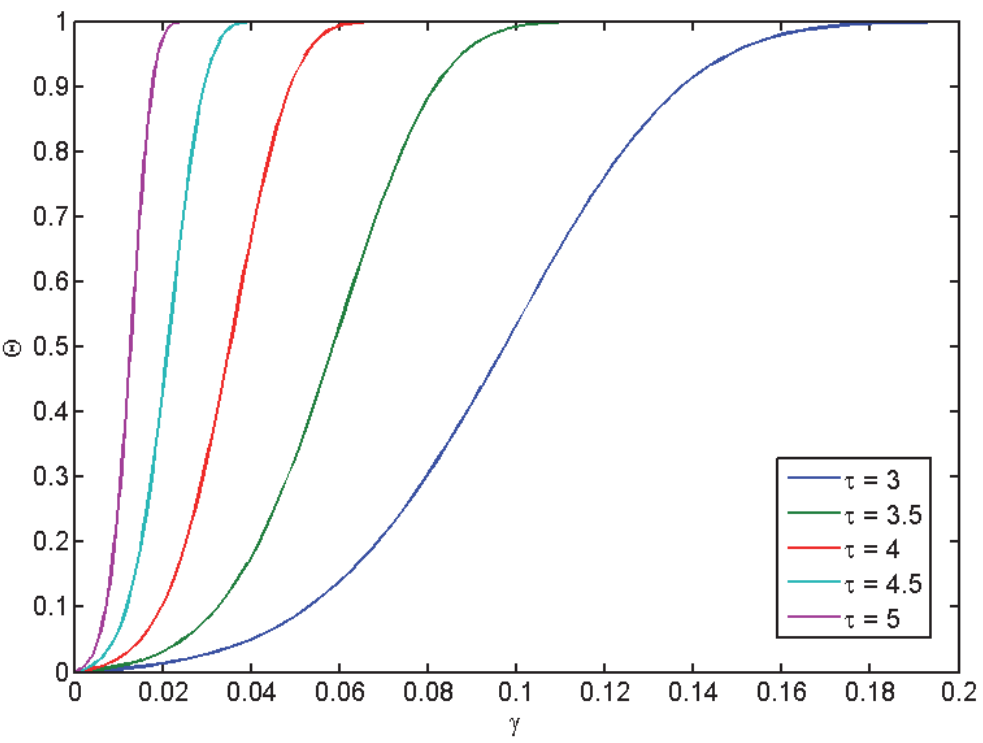

(a) $\operatorname{Pr}=3$

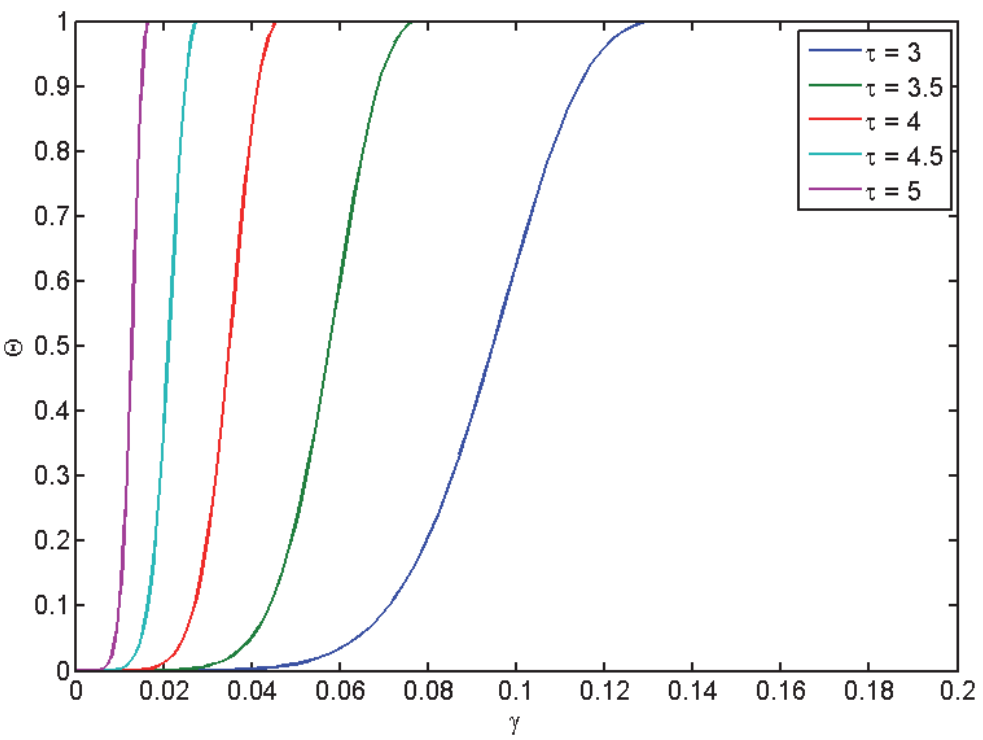

(b) $\operatorname{Pr}=10$

Fig. 10. Numerical temperature solution $\Theta$ for various value of $\gamma$ 


\section{Conclusion}

This study provides velocity and temperature distributions at different locations along the wall of a reversed stagnation-point flow by solving the numerical solution of full Navier-Stokes equations with finite difference method. Numerical findings show that velocity profiles obtained from similarity solution and numerical simulation are in tremendously good agreement and in region close to the stagnation point. Discrepancy of results in velocity profiles increases in region which is away from the reversed stagnation-point flow.

With the establishment of this frame work, the more important practical properties in engineering and technology application, like the velocity of wall is function of time, the temperature of wall is function of time and distance from wall, can be investigated and they would be the next phase of this study.

\section{References}

Burmeister, L. C. (1993). Convective heat transfer, A Wiley-Interscience publication, Wiley.

Chao, B. \& Jeng, D. (1965). Unsteady stagnation point heat transfer, J. Heat Transfer 87: 221-230.

Davey, A. (1961). Boundary-layer flow at a saddle point of attachment, Journal of Fluid Mechanics 10: 593-610.

Eckert, E. (1942). Die Berechnung des Wärmeübergangs in der laminaren Grenzschicht umströmter Körper, VDI-Forschunhsheft.

Gorla, R. (1988). The final approach to steady state in a nonsteady axisymmetric stagnation point heat transfer, Heat and Mass Transfer 22(1): 37-44.

Hiemenz, K. (1911). Die Grenzschicht an einem in den gleichförmigen Flüssigkeitsstrom eingetauchten geraden Kreiszylinder, Dingl. Polytech, J 326: 321-410.

Howarth, L. (1951). CXLIV. The boundary layer in three dimensional flow.-Part II. The flow near a stagnation point, Philosophical Magazine (Series 7) 42(335): 1433-1440.

Lok, Y., Amin, N. \& Pop, I. (2006). Mixed convection near a non-orthogonal stagnation point flow on a vertical plate with uniform surface heat flux, Acta Mechanica 186(1): 99-112.

Proudman, I. \& Johnson, K. (1962). Boundary-layer growth near a rear stagnation point, Journal of Fluid Mechanics 12(02): 161-168.

Robins, A. \& Howarth, J. (1972). Boundary-layer development at a two-dimensional rear stagnation point, Journal of Fluid Mechanics 56(01): 161-171.

Sano, T. (1981). Unsteady stagnation point heat transfer with blowing or suction, Journal of Heat Transfer 103: 448.

White, F. (2003). Fluid Mechanics. 5th edt. 


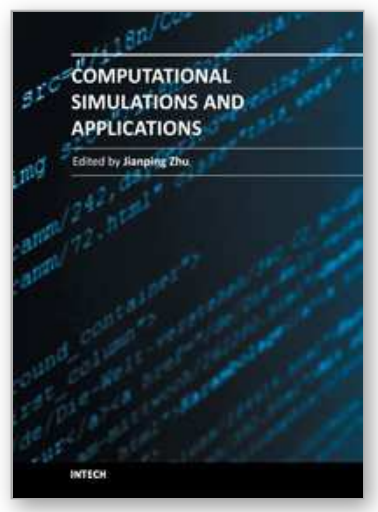

\section{Computational Simulations and Applications}

Edited by Dr. Jianping Zhu

ISBN 978-953-307-430-6

Hard cover, 560 pages

Publisher InTech

Published online 26, October, 2011

Published in print edition October, 2011

The purpose of this book is to introduce researchers and graduate students to a broad range of applications of computational simulations, with a particular emphasis on those involving computational fluid dynamics (CFD) simulations. The book is divided into three parts: Part I covers some basic research topics and development in numerical algorithms for CFD simulations, including Reynolds stress transport modeling, central difference schemes for convection-diffusion equations, and flow simulations involving simple geometries such as a flat plate or a vertical channel. Part II covers a variety of important applications in which CFD simulations play a crucial role, including combustion process and automobile engine design, fluid heat exchange, airborne contaminant dispersion over buildings and atmospheric flow around a re-entry capsule, gas-solid two phase flow in long pipes, free surface flow around a ship hull, and hydrodynamic analysis of electrochemical cells. Part III covers applications of non-CFD based computational simulations, including atmospheric optical communications, climate system simulations, porous media flow, combustion, solidification, and sound field simulations for optimal acoustic effects.

\section{How to reference}

In order to correctly reference this scholarly work, feel free to copy and paste the following:

Vai Kuong Sin and Chon Kit Chio (2011). Computation of Non-Isothermal Reversed Stagnation-Point Flow over a Flat Plate, Computational Simulations and Applications, Dr. Jianping Zhu (Ed.), ISBN: 978-953-307430-6, InTech, Available from: http://www.intechopen.com/books/computational-simulations-andapplications/computation-of-non-isothermal-reversed-stagnation-point-flow-over-a-flat-plate

\section{INTECH}

open science | open minds

\section{InTech Europe}

University Campus STeP Ri

Slavka Krautzeka 83/A

51000 Rijeka, Croatia

Phone: +385 (51) 770447

Fax: +385 (51) 686166

www.intechopen.com

\section{InTech China}

Unit 405, Office Block, Hotel Equatorial Shanghai

No.65, Yan An Road (West), Shanghai, 200040, China

中国上海市延安西路65号上海国际贵都大饭店办公楼 405 单元

Phone: +86-21-62489820

Fax: +86-21-62489821 
(C) 2011 The Author(s). Licensee IntechOpen. This is an open access article distributed under the terms of the Creative Commons Attribution 3.0 License, which permits unrestricted use, distribution, and reproduction in any medium, provided the original work is properly cited. 